\title{
Elit Genç Futbolcularda Küçük Alan Oyun Antrenmanın Hoff Test Skorlarına Etkisi
}

\author{
Abdullah GÜLLÜ ${ }^{1 *} \mathbb{D}$ \\ ${ }^{1}$ Hitit Üniversitesi, Spor Bilimleri FAKÜLTESİ, ÇORUM
}

\section{DOI: 10.31680/gaunjss.505829}

Öz

Bu araştırmanın amacı, küçük alan oyun (KAO) antrenmanlarının elit genç futbolcularda Hoff test skorlarına olan etkisini araştırmaktır. Araştırmaya, sağlıklı ve gönüllü 21 antrenmanlı elit genç erkek futbolcu katıldı. KAO antrenman programları, haftada 3 gün (Pazartesi, Çarşamba ve Cuma) olmak üzere 4 hafta süresince (toplam 12 antrenman) uygulandı. Ayrıca katılımcılara KAO öncesi ve sonrası futbola özgü Hoff testi uygulandı. Çalışma öncesi katıımcıların yaş, boy, ağırlık ve beden kütle indeksi değerleri alındı. Katılımcıların koşu mesafesi, kalp atım hızı ve yüklenme şiddeti değerleri ise KAO ve Hoff testlerinden elde edildi. İlk ve son test ortalamaları arasındaki varyanslar Tek Yönlü ANOVA testi ile belirlendi. Elde edilen değişkenler arasındaki doğrusal ilişkiler ise Pearson Korelasyon Katsayısı ile belirlendi. Testlerde $p<0.05$ düzeyi anlamlı olarak kabul edildi. Araştırma grubunun ön ve son test tüm değişkenleri arasında anlamlı düzeyde bir gelişme olduğu gözlendi $(p<0.05)$. Değişkenler arasındaki ilişkilerde ise, pozitif veya negatif yönlü orta ve çok yüksek düzey arasında ilişkilerin olduğu gözlenmiştir $(p<0.01)$. Elit genç futbolcuların koşu mesafesi, kalp atım hızı ve yüklenme şiddetlerindeki gelişmeler nedeniyle kapasitelerinin de artığı sonucuna varıldı. Ayrıca futbola özgü hareketleri içeren Hoff test skorları, elit genç futbolcuların kapasitelerini belirlemede ve antrenman programlarını hazırlamada antrenörlere yardımcı olabilir.

Anahtar Kelimeler: Futbol, Küçük alan oyunu, Hoff test, Yüklenme şiddeti, Elit genç futbolcu

\section{The Effect of Small-Sided Game Training on Hoff Test Scores in Elite Young}

\section{Soccer Players}

\begin{abstract}
The aim of this study was to investigate the effect of small-sided game (SSG) training on Hoff test scores in elite young soccer players. This study included 21 healthy and voluntary young male soccer players. SSG training programs were administered for 4 weeks (total 12 training sessions), and 3 days a week (Monday, Wednesday and Friday). In addition, the participants were taken in soccer-specific Hoff test before and after SSG. Age, height, weight and body mass index values of the participants were taken before the study. Running distance, heart rate and loading intensity values were obtained from SSG and Hoff tests. One-way ANOVA test was used to determine the variances between the first and last test means. The linear relations between the obtained variables were determined by Pearson Correlation Coefficient. $\mathrm{P}<0.05$ was considered significant in the tests. There was a significant improvement between the pre- and post-test variables of the study group $(p<0.05)$. In the relations between the variables, it was observed that there was a relationship between medium and very high level in positive or negative direction $(p<0.01)$. It was concluded that the capacity of elite young players increased due to improvements of running distance, heart rate and loading intensity. Also, the Hoff test values, which include soccer-specific movements, can help coaches in determining the capacity of elite young players and preparing their training programs.
\end{abstract}

Keywords: Soccer, Small-sided game, Hoff test, Loading intensity, Elite young soccer player

\footnotetext{
* Sorumlu Yazar: Abdullah GÜLLÜ

E-mail:abdgullu@gmail.com
} 


\section{Giriş}

Futbol, dünyanın en popüler sporudur. Uluslararası Futbol Federasyonu (FIFA)'ya göre yaklaşık 265 milyon oyuncu, 5 milyon hakem ve görevli aktif olarak bu spora katılıyor ve bu da dünya nüfusunun \%4'ünü kapsıyor demektir (Haugen ve ark., 2015). Futbol karmaşık bir spordur (Casanova ve ark., 2013). Bu oyunu rekabet edebilir bir seviyede oynamak için oyuncular, yüksek seviyede aerobik ve anaerobik kondisyona ihtiyaç duyarlar (Reilly ve ark., 2000). Profesyonel futbolculardaki aerobik kapasite seviyesi, bir maç sırasında yüksek yoğunlukta kat edilen mesafeyle ilişkilidir (Bangsbo, 1994). Birçok çalışma, \%75'lik bir şiddetle kat edilen toplam mesafenin yaklaşık 10-12 km olduğunu (McMillan ve ark., 2005) ve bunun sonucunda da oyunun toplam enerji maliyetine yaklaşık \%90 katkıda bulunduğunu ortaya koymuştur (Helgerud ve ark., 2011).

Son zamanlarda futbolcuların performanslarını artırmak için çeşitli antrenman yöntemleri geliştirilmiştir. Performansı geliştirmek için kullanılan en etkili antrenman yöntemleri ise gerçek bir futbol oyunundaki benzer koşulları içermelidir (Oh ve ark., 2018). Bunun yanında, seçkin futbolcular için antrenman uygulamaları belirli teknik, taktik ve fiziksel bileşenleri göz önünde bulundurmalıdır. Bu taleplerin bir sonucu olarak, küçük alanlı oyunlar (KAO) hem fiziksel hem de teknik çalışmaları içeren futbol çalışmalarında daha yüksek verim alınmasını (Fanchini ve ark., 2011; Yanga ve ark., 2018) ve maç sırasında karşılaşılan talepleri sağlayan popüler bir şartlandırma aracı haline gelmiştir (Christopher ve ark., 2016). Ayrıca 5'e karşı 5 (5x5) oyundaki aktivite sırasındaki kalp atım hızı (KAH) değişikliklerinin ve topla temas sayılarının, eşit bir koşu mesafesine rağmen 11'e karşı 11 oyundakilerden önemli ölçüde daha yüksek olduğu (Allen ve ark., 1998) belirtilmiştir. Bu antrenman yöntemi, topun KAO sırasındaki mevcudiyetinin bir sonucu olarak, oyuncuların daha fazla motivasyonu ile birlikte teknik ve taktik becerilerin geliştirilmesine de olanak sağlamaktadır (Dellal ve ark., 2008). Bunun yanında çeşitli KAO antrenmanları esnasındaki KAH cevapları, futbolcuların çalışma şiddetlerini yansıtması bakımından geçerli bir yöntemdir (Hoff ve ark., 2002).

Futbolcuların aerobik dayanıklılığının değerlendirilmesinin ana eleştirisi, kullanılan testlerin (sürekli koşu, koşu parkuru veya koşu bandı koşuları gibi) futbolda gerçekleştirilen birçok teknik özellikleri ölçemediğidir (Zagatto ve ark., 2016). Bu nedenle Hoff testi (Hoff ve ark., 2002), teknik kapasite ile yakından ilişkili olan top ile geri dönüşler ve yön değiştirmeler içeren özel bir devre önermiştir (Castagna ve ark., 
2010). Hoff testi ayrıca, maksimum kalp atım hızını (KAHmax) (Kemi ve ark., 2003) belirlemek için ve futbolda gerçekleştirilen koşu mesafesini tahmin etme olasılığı ile yüksek oranda pratik bir uygulanabilirlik sağlayacaktır (Zagatto ve ark., 2013). Ek olarak, bazı yazarlar Hoff devresini alternatif aerobik antrenmanı olarak ve ilgili KAH futbolcuların antrenmanını izlemek için geçerli ve güvenilir bir gösterge olarak önermektedir (Hoff ve ark., 2002; Zagatto ve ark., 2016).

Farklı seviyelerdeki oyuncuların fizyolojik özelliklerini belirlemeye yönelik çok sayıda çalışma vardır (Redkva ve ark., 2018). Ancak futbol dünyada en çok oynanan sporlardan biri olmasına rağmen, genç oyuncuların kapasiteleri ve futbol performansları ile ilgili çalışmalar hala çok kısıtıdır (Rodrigo ve ark., 2010). KAO futbol antrenmanları sporcuların fiziksel ve fizyolojik kapasitelerini, teknik ve taktik kapasitelerini ve mental hazırlık statülerini geliştirmeye olanak sağlamaktadır. Bu nedenle; (1) sporcuların 5x5 KAO futbol antrenmanlarındaki KAH cevaplarını, (2) sporcuların 10 dakikalık Hoff testindeki KAH cevaplarını, (3) sporcuların Hoff testindeki toplam koşu mesafesini ve (4) sporcuların KAO ve Hoff test yüklenme şiddeti cevaplarının araştırılması planlandı. Bu amaçlar doğrultusunda bu çalışma, haftada 3 gün olmak üzere 4 hafta süresince uygulanan KAO futbol antrenmanları Elit A U19 genç takım futbolcularının Hoff test skorlarına olan etkisini incelemek için gerçekleştirilmiştir.

\section{Yöntem}

\section{Araştırma grubu}

Bu çalışmaya, Elit A U19 Ligi (Türkiye Futbol Federasyonu (TFF) Süper Lig Kulüplerinin U19 takımlarından oluşturduğu lig) grubunda yer alan toplam 24 elit genç erkek futbolcu gönüllü olarak katıldı. Çalışmalara katılan 3 kaleci değerlendirme dışı bırakıldı. Ayrıca herhangi bir ilaç tedavisi almayan ve akut veya kronik herhangi bir hastalığı olmayan toplam 21 antrenmanlı elit genç erkek futbolcu çalışmaya alındı. Müdahale grubunun ortalama $(X \pm S S$ ) fiziksel değerleri; yaş $17.10 \pm 0.77$ yıl, boy $175.95 \pm 4.52 \mathrm{~cm}$, ağırlık $70.63 \pm 4.62 \mathrm{~kg}$ ve spor yaşı $9.24 \pm 1.18$ yıl idi. Çalışmalara başlamadan önce, kulüp yönetiminden ve kulüp doktorundan sporcuların antrenmanlara ve testlere katılmasında sakınca olmadığına dair yazılı onaylar alındı. Daha sonra, Helsinki Deklarasyonu'ndaki kurallara uygun olarak hazırlanmış çalışmayla ilgili potansiyel riskler ve rahatsızlıklar hakkında bilgi veren form imzalı 
olarak alındı. Antrenman programları öncesinde (ön-test) ve sonrasında (son-test) yapılan tüm testler 4 hafta arayla ve aynı sırayla tamamlandı.

\section{Küçük alan oyunları (KAO) antrenman programları}

KAO futbol antrenmanları, Elit A U19 genç takım futbolcularının Hoff test skorlarına olan etkisini incelemek için gerçekleştirilmiştir. Bunun için oyuncular haftada beş gün antrenman yaptılar ve müdahale döneminde müsabakalara katılmadılar. KAO, 5'e karşı 5 oyuncu (5x5) şeklinde hedefli (kalecileri ile birlikte nizami ölçülerde iki futbol kalesi) olarak iki takım arasında oynandı (Fransson ve ark., 2018). $5 \times 5$ KAO antrenman programları, haftada 3 gün (Pazartesi, Çarşamba ve Cuma) olmak üzere 4 hafta süresince (toplam 12 antrenman) uygulandı. KAO antrenman programları, sentetik çim yüzeyli açık alan futbol sahasında $30 \mathrm{~m}$ genişliğinde ve $45 \mathrm{~m}$ uzunluğunda bir alan içerisinde (Brito ve ark., 2012) gerçekleştirildi. KAO, planlanan rutin antrenman programlarının içeriğinde herhangi bir değişiklik yapılmadan, birim antrenman programı içerisinde yer aldı ve toplam olarak 15 dakikalık bir süreyi kapsadı. Dinlenme aralıkları, sporcuların çalışmayı sürdürmek ve yorgunluğun etkisini en aza indirmek amacıyla (Kyle ve ark., 2018), KAH'ların 120 atım/dk 'ya gelene kadar pasif+aktif kombinasyonlu dinlenme metodu uygulandı (Tablo 1).

Tüm KAO, oyuncunun mevkisi dikkate alınmadan oynandı ve futbolun genel kurallarında herhangi bir değişiklik yapılmadı. Elit A U19 takımı teknik sorumlusu (TFF' nin "Teknik Adam Uygunlukları" kriterlerine uygun UEFA-A lisansına sahip) 5 yıllık antrenörlük deneyimine sahipti ve 2 yıldır bu grubun teknik sorumluluk görevini yürütüyordu.

Tablo 1: Küçük Alan Oyun Antrenman Programı"

\begin{tabular}{cccl}
\hline Set sayısı & Tekrar SayıSı & Çalışma/Yüklenme süresi & Dinlenme Aralığı \\
\hline 1 & 2 & $5 \mathrm{dk}$ & $\begin{array}{l}\text { KAH 120 atım/dk'ya gelene kadar } \\
\text { pasif+aktif kombinasyonu dinlenme } \\
\text { metodu uygulanmıştır. }\end{array}$ \\
\hline
\end{tabular}

${ }^{\#}$ Antrenman Sıklı̆ı: 3 gün/hafta (Pazartesi, Çarşamba, Cuma)

Hoff test: İçerisinde topla yapılan hareketler, sıçramalar, yön değiştirmeli koşular ve sprintler bulunan futbola özgü bir saha testidir. Testin amacı $10 \mathrm{dk}$ süre içerisinde en fazla mesafeyi kat etmektir. Hoff testinde kullanılan model Şekil 1 'de sunulmuştur (Hoff ve ark., 2002). 
Hoff test protokolü: Testin bir turu toplam 290 m'dir ve sırasıyla 49m, $186 m$ ve $55 \mathrm{~m}$ mesafeleri içeren üç aşamadan oluşmaktadır. Test topla yapılan driplingle başlar ve $30 \mathrm{~cm}$ yüksekliğindeki engellerin üzerinden geçtikten sonra sırasıyla 1 , 2, 3, 4, 5 ve 6 numaralı zikzak yerleştirilmiş hunilerden geçer. Daha sonra, 7. ve 8. hunilerin arasında geri geri koşar ve dönerek ileri doğru diğer huniye geçer. Son olarak da turu tamamlamak için başlangıç noktasına koşar.

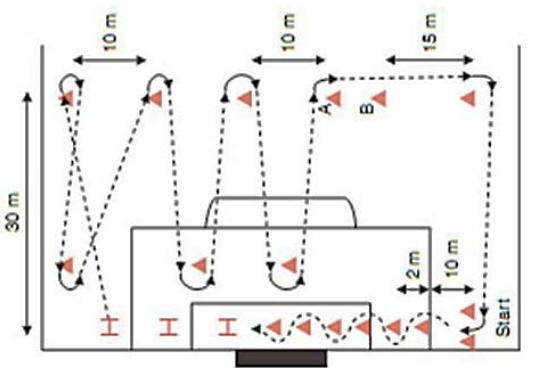

Şekil 1: Hoff test modeli

Fiziksel testler: Araştırma grubunun fiziksel özellik testleri KAO antrenmanları öncesinde bir defa alındı. Katılımcıların boyları, postürleri dik pozisyonda ve çıplak ayak olarak $\pm 0.01 \mathrm{~cm}$ hassasiyetinde mezura ile ölçüldü. Deneklerin vücut ağırlığı ve beden kütle indeksi (BKI) değerleri şort, tişört ve çıplak ayak olarak vücut kompozisyonu ölçüm cihazından (Tanita BC-418 MA, Japan) otomatik çıktı alınarak belirlendi.

Koşu mesafesi ölçümü: Katılımcının Şekil 1' deki Hoff testinde 10 dk süre içerisinde ulaştığı toplam mesafe, koşu mesafesi olarak metre cinsinden kaydedildi.

Kalp atım hızı (KAH) ve yüklenme şiddeti (YŞ) ölçümü: Araştırma grubunun KAH ve YŞ değerleri KAO antrenmanları ve Hoff testlerinden elde edildi. Araştırma grubunun KAH değerleri, portatif kalp atım monitörü (Polar S810i, Oy, Kempele, Finland) ile atım/dakika cinsinden kaydedildi. Her bir sporcunun Hoff test ve $5 \times 5$ KAO antrenmanlarındaki YŞ değerlerini belirlemek için Karvonen Metodu (Brouwer ve ark., 2018) kullanıldı.

$\mathrm{KAHhdf}=\mathrm{I} \mathrm{KAH}+(\mathrm{KAHmax}-\mathrm{I} \mathrm{KAH}) \times \mathrm{YS}$

KAHhdf: Hedef kalp atım hızı; IKAH: İstirahat kalp atım hızı; KAHmax: Maksimal kalp atım hızı (220 - yaş)

\section{Verilerin analizi}

Elde edilen verilerin tanımlayıcı istatistikleri yapılarak metin içerisinde ortalama ve standart sapma $(X \pm S S)$ şeklinde verildi. Tüm verilerin normallik sınamaları için Shapiro-Wilk testi kullanıldı. Tüm veriler normal dağılım gösterdiği için ( $p>0.05)$, parametrik testler uygulandı. Katılımcıların ilk ve son test ortalamaları arasındaki varyanslar Tek Yönlü ANOVA testi ile belirlendi. Fiziksel ve metabolik değişkenler arasındaki doğrusal ilişkiler ise Pearson Momentler Çarpımı Korelasyon Katsayısı ( $r$ ) 
ile belirlendi. Araştırmanın istatistiksel hesaplamaları IBM SPSS 25.0 paket programı ile yapıldı ve bütün testlerde $p<0.05$ düzeyi anlamlı olarak kabul edildi.

\section{Bulgular}

Elit genç futbolculara uygulanan KAO futbol antrenmanları öncesi ve sonrası elde edilen fiziksel özellik, KAH, koşu mesafesi ve yüklenme şiddeti değerleri Tablo 2, 3 ve 4 'te verilmiştir.

Tablo 2: Araştırma grubunun fiziksel ve metabolik özelliklerinin tanımlayıcı bilgileri

\begin{tabular}{lcccc}
\hline Değişkenler & $\mathrm{N}$ & Minimum & Maximum & $\mathrm{X} \pm \mathrm{SS}$ \\
\hline Yaş (yıl) & 21 & 16 & 18 & $17.10 \pm 0.77$ \\
Boy (cm) & 21 & 168 & 186 & $175.95 \pm 4.52$ \\
Ağırlık (kg) & 21 & 60.3 & 77 & $70.63 \pm 4.62$ \\
Spor Yaşı(yıl) & 21 & 7 & 12 & $9.24 \pm 1.18$ \\
BKi (kg/m²) & 21 & 20.38 & 23.71 & $22.79 \pm 0.72$ \\
IKAH (atım/dk) & 21 & 52 & 68 & $61.14 \pm 4.54$ \\
KAHmax (atım/dk) & 21 & 202 & 204 & $202.90 \pm 0.77$ \\
\hline
\end{tabular}

Tablo 3: Araştırma grubunun ön ve son test değişkenlerinin tanımlayıcı istatistikleri ve grup içi ANOVA karşılaştırmaları

\begin{tabular}{|c|c|c|c|c|c|c|c|}
\hline \multirow[b]{2}{*}{ Değişkenler } & \multirow[b]{2}{*}{ Testler } & \multirow[b]{2}{*}{$\mathrm{N}$} & \multicolumn{5}{|c|}{ Ortalamanın \%95 Güven Aralığı } \\
\hline & & & $\mathrm{X} \pm \mathrm{SS}$ & Alt Sınır & Üst Sınır & $\mathrm{F}$ & $p$ \\
\hline \multirow{3}{*}{$\begin{array}{l}\mathrm{KAO}-\mathrm{KAH} \\
\text { (atım/dk) }\end{array}$} & Ön & 21 & $175.97 \pm 1.03$ & 175.50 & 176.44 & \multirow{3}{*}{572.21} & \multirow{3}{*}{$0.00^{*}$} \\
\hline & Son & 21 & $183.06 \pm 0.89$ & 182.66 & 183.46 & & \\
\hline & Toplam & 42 & $179.51 \pm 3.71$ & 178.36 & 180.67 & & \\
\hline \multirow{3}{*}{$\begin{array}{l}\text { Hoff Test-KAH } \\
\text { (atım/dk) }\end{array}$} & Ön & 21 & $194.40 \pm 0.75$ & 194.06 & 194.74 & \multirow{3}{*}{320.02} & \multirow{3}{*}{$0.00^{*}$} \\
\hline & Son & 21 & $190.15 \pm 0.79$ & 189.79 & 190.50 & & \\
\hline & Toplam & 42 & $192.27 \pm 2.28$ & 191.56 & 192.98 & & \\
\hline \multirow{3}{*}{$\begin{array}{l}\text { Hoff Test } \\
\text { Mesafe }(\mathrm{m})\end{array}$} & Ön & 21 & $1465.61 \pm 176.54$ & 1385.25 & 1545.97 & \multirow{3}{*}{22.18} & \multirow{3}{*}{$0.00^{*}$} \\
\hline & Son & 21 & $1722.14 \pm 176.49$ & 1641.81 & 1802.48 & & \\
\hline & Toplam & 42 & $1593.88 \pm 217.37$ & 1526.14 & 1661.61 & & \\
\hline \multirow{3}{*}{ KAO şiddeti (\%) } & Ön & 21 & $81 \pm 0.00$ & 81 & 81 & \multirow{3}{*}{764.27} & \multirow{3}{*}{$0.00^{\star}$} \\
\hline & Son & 21 & $86 \pm 0.00$ & 86 & 86 & & \\
\hline & Toplam & 42 & $84 \pm 0.03$ & 83 & 84 & & \\
\hline \multirow{3}{*}{$\begin{array}{l}\text { Hoff Test } \\
\text { şiddeti (\%) }\end{array}$} & Ön & 21 & $94 \pm 0.00$ & 94 & 94 & \multirow{3}{*}{357.05} & \multirow{3}{*}{$0.00^{*}$} \\
\hline & Son & 21 & $91 \pm 0.00$ & 91 & 91 & & \\
\hline & Toplam & 42 & $93 \pm 0.02$ & 92 & 93 & & \\
\hline
\end{tabular}

${ }^{\star} p<0.05 ;$ KAO-KAH: Küçük alan oyunları kalp atım hızı

Araştırma grubunun ön ve son test değişken ortalamalarının \%95 güven aralığındaki grup içi ANOVA karşılaştırmasında; bütün değişkenler arasında anlamlı düzeyde bir gelişme olduğu gözlenmiştir $(p<0.05$; Tablo 3 ). 
Tablo 4: Araştırma grubunun KAO ve Hoff Test değişkenleri arasındaki ilişki düzeyleri

\begin{tabular}{lcccc}
\hline Değişkenler & Hoff Test Mesafe & Hoff Test KAH & KAO Şiddeti & Hoff Test Şiddeti \\
\hline KAO-KAH & $0.50^{\star \star}$ & $-0.84^{\star \star}$ & $0.97^{\star \star}$ & $-0.97^{\star \star}$ \\
Hoff Test Mesafe & 1 & $-0.61^{\star \star}$ & $0.60^{\star \star}$ & $-0.60^{\star \star}$ \\
Hoff Test KAH & & 1 & $-0.94^{\star \star}$ & $0.94^{\star \star}$ \\
KAO Şiddeti & & & 1 & $-0.99^{\star \star}$ \\
\hline
\end{tabular}

${ }^{\star \star} p<0.01 ; K A O-K A H:$ Küçük alan oyunları kalp atım hızı

Genel olarak, KAO antrenmanları ve Hoff testlerden elde edilen değişkenlerin \%99 güven aralığındaki grup içi ortalamaları arasındaki ilişki düzeylerine bakıldığında; pozitif veya negatif yönlü orta $(r=0.50 ; p<0.01)$ ve çok yüksek $(r=-0.99$; p<0.01) düzey arasında ilişkilerin olduğu gözlenmiştir (Tablo 4).

\section{Tartışma}

Elit A U19 genç takım futbolcularına uygulanan 5x5 KAO antrenman programlarının (Tablo 1) birincil amacı, antrenmanlar esnasındaki $\mathrm{KAH}$ ve yüklenme şiddeti değişimlerini incelemekti. İkincil amaç ise, KAO (12 antrenman) öncesi ve sonrasında elit genç futbolcuların koşu mesafesi, KAH cevapları ve yüklenme şiddetindeki olası gelişimleri Hoff testi sonuçlarına göre incelemekti. Böylelikle Elit A U19 genç takım futbolcuları, Tablo 1'de belirtilen 5x5 KAO antrenmanlarını haftada 3 gün olmak üzere 4 hafta süresince uyguladılar. Araştırma grubumuzun ön ve son test ortalama KAO-KAH değerlerinin \%95 güven aralığındaki ANOVA karşılaştırmasında anlamlı düzeyde bir gelişme olduğu belirlenmiştir ( $p<0.05$; Tablo 3). \%99 güven aralığındaki KAO-KAH ile diğer değişkenler arasındaki ilişki düzeylerine bakıldığında ise; genel olarak pozitif veya negatif yönlü orta $(r=0.50 ; p<0.01)$ ve çok yüksek ( $r=-$ 0.99; p<0.01) düzey arasında değişen ilişkilerin olduğu gözlenmiştir (Tablo 4).

Performansı geliştirmek için kullanılan en etkili antrenman yöntemleri, gerçek bir futbol müsabakasındaki benzer koşulları içermesi gerektiğinden (Oh ve ark., 2018), KAO programları resmi müsabakalara yakın bir ilişki içerisinde ve genç oyuncuların fiziksel ve teknik gelişimlerini sağlamak için özel bir araç olarak kullanıldığı (Jones ve ark., 2007) söylenebilir. Böylece, KAO’ da yapılan fiziksel ve teknik içerikli futbol çalışmalarında daha yüksek verim alınmasına katkıda bulunduğu (Fanchini ve ark., 2011; Yanga ve ark., 2018) düşünülebilir. Çünkü, KAO antrenmanlarında oyuncuların topla teknik ve taktik becerilerini kullanma çabaları, onların motivasyonlarının daha fazla artmasını sağlamaktadır (Dellal ve ark., 2008). Ayrıca eşit düzeyde bir koşu mesafesine rağmen, KAO sırasındaki KAH 
değişikliklerinin ve $5 \times 5$ oyunundaki top temas sayılarının, normal müsabaka $(11 \times 11)$ oyunlarından daha yüksek olduğu (Allen ve ark., 1998) belirtilmiştir. Bu durumda KAO antrenmanları, resmi müsabakaların bir simülasyonu (Abrantes ve ark., 2012) şeklinde tanımlanabilir. Bu da oyuncuların KAO esnasında yüksek konsantrasyon ve top teması (Dellal ve ark., 2011) ile birlikte KAH değerlerini amaca yönelik şekilde yükselmesine neden olabilir. Bunun yanında, KAO sırasında rakiple olan sürekli mücadele durumları, sporcuların $\mathrm{KAH}$ yanıtlarını doğrudan etkilediğinden (Allen ve ark., 1998), antrenman şiddetindeki zorluk derecesinin de bir göstergesidir (Hoff ve ark., 2002) denebilir. Bu gözlemlerin bir sonucu olarak, elit genç sporcuların hem dayanıklılık hem de yüksek şiddetteki KAO performanslarına karşı organizmaları uygun adaptasyon (Fransson ve ark., 2018) cevapları vermiş olabilir. Bu durumlar KAO yüklenme şiddeti $(r=0.97 ; p<0.01)$ ile Hoff $\mathrm{KAH}(r=-0.84 ; p<0.01)$ arasında yüksek düzeyde bir ilişkinin bulunmasını açıklayabilir.

Hoff ve arkadaşları tarafından önerilen test (Hoff ve ark., 2002), devamlı olarak top teması ile gerçekleştirilen top sürme, farklı yönlerde yer değiştirme ve test esnasında kat edilen toplam mesafeler oyun sırasında gerçekleştirilen aktiviteleri simüle etmeye çalışmak amacıyla tasarlanmıştır (Zagatto ve ark., 2013). Bunun yanında, farklı seviyelerdeki oyuncuların fizyolojik özelliklerini belirlemeye yönelik çok sayıda çalışma olmasına rağmen, Hoff testinin toplam olarak daha fazla mesafeyi kapsadığı ve daha fazla sayıda yüksek yoğunluklu aktivite gerçekleştirdiği (Redkva ve ark., 2018) sonucuna varılmıştır. Zaten bir futbol maçı da kısa toparlanma süreleri ile aralıklı ve yüksek şiddetteki aktivitelerle karakterizedir. Bu nedenle oyuncular, oyun sırasında daha fazla sayıda sprint yapar ve daha fazla mesafe kat ederler. Böylece, Hoff testini kullanarak aerobik dayanıklılık ve anaerobik eşik (Zagatto ve ark., 2016), KAH (Dellal ve ark., 2008) ve koşu mesafesi (Dellal ve ark., 2008; Zagatto ve ark., 2013) gibi kapasiteleri değerlendirmek mümkündür. Bu önemli bir bulgu, çünkü bu özel yöntem muhtemelen futbolcular ve uygulayıcılar tarafından çok daha fazla takdir ve kabul görmektedir (Zagatto ve ark., 2016). Futbol gibi yüksek yoğunluklu interval bir sporda, fiziksel talepler karmaşıktır. Bu yüksek şiddetteki egzersiz sırasında hem yüksek dayanıklılık kapasitesi, hem de yorulma direnci içerir (Fransson ve ark., 2018). Bu nedenle KAO, beceri yeterliliğini ölçmek için çok boyutlu bir test bataryasının bir parçası olarak uygulanabilir (Kyle ve ark., 2018). Çünkü KAO, kısa süreli oyunlar sayesinde oyuncuların beceri yeterliliğinin uygun bir şekilde değerlendirilmesine olanak sağlayabilir. Bu durumda KAO 'da yer alan takımlar 
oyunun getirdiği problemleri çözmeleri amacıyla, oyuncuların teknik ve taktiksel stratejilerini keşfetmelerine ve onları geliştirmesine olanak sağlar (Fanchini ve ark., 2011; Yanga ve ark., 2018). Yüksek düzeydeki bir müsabakada kat edilen toplam mesafenin yaklaşık 10-12 km olduğunu (McMillan ve ark., 2005) düşündüğümüzde, toplam koşu mesafesinin rakibe olan üstünlüğü kanıtlayan önemli bir belirleyici olarak düşünülebilir. Zaten 5x5 KAO aktivitelerinde kat edilen toplam koşu mesafesine bakıldığında, 11'e karşı 11 oyundakilerden önemli ölçüde daha yüksek olduğu (Allen ve ark., 1998) da ayrıca belirtilmektedir. Bu açıklamaların bir sonucu olarak, Hoff test mesafe değerlerinin \%95 güven aralığındaki ANOVA karşılaştırmasında anlamlı düzeyde bir gelişmeye ( $p<0.05$; Tablo 3 ) katkı sunabileceği düşünülebilir. Buna bağlı olarak \%99 güven aralığındaki diğer değişkenler arasındaki ilişki düzeylerinde anlamlı ilişkilerin gerçekleşmesine (Tablo 4) neden olmuştur denebilir.

Elit A U19 genç takım futbolcuları için antrenman uygulamaları belirli teknik, taktik ve fiziksel bileşenleri göz önünde bulundurmalıdır (Christopher ve ark., 2016). Bu yüzden, KAO çalışmalarında sadece yüzey (doğal çim) değil, aynı zamanda sürekli koşuya karşı belirli futbol hareketleri de sentetik yüzeyli bir sahada uygulanmıştır. Bu nedenle, KAO’lar esnasında topla yapılan kontrol, pas, dripling, şut, kafa vurma, çalım atma vs. gibi maçlara özgü hareketlerin kullanılması zorunluluğu, kullanılan tekniklerin taleplerini daha spesifik hale getirmiş ve böylece birim antrenmanların verimliliğini (Jones ve ark., 2007) artırmış olabilir. Buna bağlı olarak belli bir çalışma hızında enerji maliyetini artırmış ve böylece laktat konsantrasyonunu da artırmış (Zagatto ve ark., 2016) olabilir. Bu ve benzeri durumlara organizmanın verdiği tepkiler ve etkilere olan adaptasyonlara bakıldığında, $\mathrm{KAH}$ ve algılanan çabanın derecesinin benzer olduğunu vurgulamak önemlidir (Zagatto ve ark., 2016). Bu nedenle, Hoff ve arkadaşları (Hoff ve ark., 2002), top performansı (Hoff devresi) ile eşleştiği ve performansla ilişkili olduğu gösterilen geri dönüşler ve yön değiştiren özel bir devre önermiştir (Castagna ve ark., 2010). Bu test ayrıca futbolcuların KAH (Hoff ve ark., 2002) ve KAHmax değerlerini (Kemi ve ark., 2003) belirlemek için de faydalıdır. Ancak bizim çalışmada Hoff testindeki KAH değerlerinin, KAO gibi spesifik futbol antrenmanları esnasında gerçekleşen KAH 'tan daha yüksek olduğu gözlenmiştir. Bu aynı zamanda aerobik değişimlere neden olan aerobik dayanıklılığın (Zagatto ve ark., 2016) bir sonucu şeklinde de açıklanabilir. Çünkü elit genç futbolcuların ön ve son test ortalama Hoff test KAH değerlerinin \%95 güven aralığındaki ANOVA karşılaştırmasında anlamlı düzeyde bir gelişme olduğu 
bulunmuştur $(\mathrm{p}<0.05$; Tablo 3$)$. Ayrıca Hoff test $\mathrm{KAH}$ değerinin \%99 güven aralığındaki diğer değişkenler arasındaki ilişki düzeylerine bakıldığında ise çok yüksek düzeyde $(r=-/+0.94 ; p<0.01)$ ilişkilerin olduğu gözlenmiştir (Tablo 4). Bu nedenle her ne kadar KAH değişkenleri arasında fark olsa da, 4 hafta (12 antrenman) süresince uygulanan rutin antrenmanlar ve KAO uygulamaları elit genç futbolcuların $\mathrm{KAH}$ kapasitelerini olumlu yönde etkilediğini düşündürmektedir.

Araştırma grubumuzun ön ve son test ortalama KAO ve Hoff Test şiddet değerlerinin \%95 güven aralığındaki ANOVA karşılaştırmasında anlamlı düzeyde bir gelişme olduğu gözlendi ( $p<0.05$; Tablo 3 ). KAO ve Hoff Test şiddet değerinin \%99 güven aralığındaki diğer değişkenler arasındaki ilişki düzeylerine bakıldığında ise; genel olarak pozitif veya negatif yönlü orta ve çok yüksek düzey arasında ilişkilerin olduğu gözlenmiştir (Tablo 4). Buna neden olarak, KAO antrenmanlarına katılan oyuncuların ifadelerine göre KAO' nun resmi müsabakaya benzer bir etkiden (Kyle ve ark., 2018) kaynaklandığı gösterilebilir. Bu durum, KAO 'lar normal veya resmi maçlar sırasında karşılaşılan durumları karşılayan popüler bir antrenman modeli haline geldiğini (Christopher ve ark., 2016) düşündürmektedir. Dolayısı ile, elit genç futbolculara uygulanan KAO antrenmanları belirli teknik, taktik ve fiziksel bileşenleri göz önünde bulundurmuş (Christopher ve ark., 2016) ve performansı geliştirmek için gerçek bir futbol oyunundaki benzer koşulları içermiştir (Oh ve ark., 2018) denilebilir. Ek olarak, çeşitli KAO sırasındaki KAH değerlerine (Hoff ve ark., 2002) ve Hoff testi sonuçlarına (Hoff ve ark., 2002; Zagatto ve ark., 2016; Castagna ve ark., 2003) göre futbolcuların yüklenme şiddetlerini belirlemek için geçerli bir antrenman yöntemi olarak kullanılabileceği (Christopher ve ark., 2016) belirtilmiştir. Bu açıklamaların bir sonucu olarak, KAO ve Hoff testlerinde elde edilen KAH değerleri, futbolcuların Karvonen metoduna göre (Brouwer ve ark., 2018) belirlenen antrenman/yüklenme şiddetini yansıtması açısından önemliydi. Bu nedenle, haftada üç gün ve 4 hafta (12 antrenman) süresince uygulanan rutin antrenmanlar ve KAO uygulamaları, Elit A U19 genç takım futbolcularının $\mathrm{KAH}$ kapasitelerini olumlu yönde etkilediğinden, KAO antrenman şiddeti \%86 'dan \% 81 'e ve Hoff Test yüklenme şiddeti ise \% 94 'den \% 91 'e düşmesini doğrudan etkilemiştir denebilir.

Sonuç olarak, Elit genç futbolcuların daha fazla mesafe kat etmelerine rağmen, kalp atım hızları ve uygulanan çalışma şiddetleri düştüğü için fizyolojik kapasitelerinde gelişme olduğu sonucuna varıldı. Bu nedenle küçük alan oyunları antrenörlere, genç futbolcuların fiziksel ve fizyolojik kapasitelerinin yanı sıra futbola 
özgü becerilerini pratik bir ortamda geliştirmesinin basit bir yolunu sunabilir. Ayrıca Hoff test futbola özgü hareketleri içerdiğinden, genç futbolcuların kapasitelerinin belirlenmesinde ve antrenman programlarının hazırlanmasında yardımcı bir test olarak kullanılabilir.

\section{Teşekkür}

Çalışma boyunca zaman ayırmaları, çabaları ve kararlı katııımlarından dolayı tüm antrenörlere, futbolculara ve Yeni Malatyaspor kulüp yöneticilerine teşekkür ederim.

\section{Kaynaklar}

Abrantes, C.I., Nunes, M.I., Macxãs, V.M., Leite, N.M., Sampaio, J.E., (2012). Effects of the number of players and game type constraints on heart rate, rating of perceived exertion, and technical actions of small-sided soccer games. J Strength Cond Res, 26 (4): 976-981.

Allen, J.D., Butterfly, R., Welsh, M.A., Wood, R., (1998). The physical and physiological value of 5 -a-side soccer training to 11 -a-side match play. J Hum Movement Stud, 34: 1-11.

Bangsbo, J., (1994). Energy demands in competitive soccer. J Sport Sci, 12: 5-12.

Bennett, K.J.M., Novak, A.R., Pluss, M.A., Stevens, C.J., Coutts, A.J., Fransen, J., (2018). The use of small-sided games to assess skill proficiency in youth soccer players: a talent identification tool, Science and Medicine in Football, 2 (3): 231-236.

Brito, J., Krustrup, P., Rebelo, A., (2012). The influence of the playing surface on the exercise intensity of small-sided recreational soccer games. Human Movement Science, 31 (4): 946-956.

Brouwer, A.M., Van Dam, E., Van Erp, J.B.F., Spangler, D.P., Brooks, J.R., (2018). Improving real-life estimates of emotion based on heart rate: a perspective on taking metabolic heart rate into account. Front Hum Neurosci, 12: 284. eartical

Casanova, F., Garganta, J., Silva, G., Alves, A., Oliveira, J., Williams, A.M., (2013). Effects of prolonged intermittent exercise on perceptual-cognitive processes. Med Sci Sports Exerc, 45 (8): 1610-1617. 
Castagna, C., Manzi, V., Impellizzeri, F., Weston, M., Alvarez, J.C.B., (2010). Relationship between Endurance Field Tests and Match Performance in Young Soccer Players. J Strength Cond Res. 24 (12): 3227-33.

Christopher, J., Beato, M., Hulton, A.T., (2016). Manipulation of exercise to rest ratio within set duration on physical and technical outcomes during small-sided games in elite youth soccer players. Hum Mov Sci. 48: 1-6. e-artical

Dellal, A., Chamari, K., Owen, A.L., Wong, D.P., Lago-Penas, C., Hill-Haas, S., (2011). Influence of technical instructions on the physiological and physical demands of small-sided soccer games. European Journal of Sport Science, 11 (5): 341-346.

Dellal, A., Chamari, K., Pintus, A., Girard, O., Cotte, T., Keller, D., (2008). Heart rate responses during small-sided games and short intermittent running training in elite soccer players: a comparative study. J Strength Cond Res, 22 (5): 14491457.

Fanchini, M., Azzalin, A., Castagna, C., Schena, F., Mccall, A., Impellizzeri, F.M., (2011). Effect of bout duration on exercise intensity and technical performance of small-sided games in soccer. Journal of Strength and Conditioning Research, 25 (2): 453-458.

Fransson, D., Nielsen, T.S., Olsson, K., Christensson, T., Bradley, P.S., Fatouros, I.G., Krustrup, P., Nordsborg, N.B., Mohr, M., (2018). Skeletal muscle and performance adaptations to high-intensity training in elite male soccer players: speed endurance runs versus small-sided game training. Eur J Appl Physiol, 118 (1): 111-121.

Haugen, T., Seiler, S., (2015). Physical and physiological testing of soccer players: why, what and how should we measure? Sport science, 19: 10-26. e-artical Helgerud, J., Engen, L.C., Wisloff, U., Hoff, J., (2011). Aerobic endurance training improves soccer performance. Med Sci Sports Exerc, 33 (11): 1925-1931.

Hoff, J., Wisløff, U., Engen, L.C., Kemi, O.J., Helgerud, J., (2002). Soccer specific aerobic endurance training. $\mathrm{Br} \mathrm{J}$ Sports Med, 36: 218-221. e-artical

Jones, S., Drust, B., (2007). Physiological and technical demands of $4 \mathrm{v} 4$ and $8 \mathrm{v} 8$ games in elite youth soccer players. Kinesiology, 39 (2): 150-156.

Kemi, O.J., Hoff, J., Engen, L.C., Helgerud, J., Wisloff, U., (2003). Soccer specific testing of maximal oxygen uptake. J Sports Med Phys Fitness, 43 (2): 139-44. 
McMillan, K., Helgerud, J., Grant, S., Newell, J., Wilson, J., McDonald, R., Hoff, J., (2005). Lactate threshold responses to a season of professional British youth soccer. Br J Sports Med, 39 (7):432-436.

Oh, S.H., Joo, C.H., (2018). Comparison of technical and physical activities between 8 vs. 8 and 11 vs. 11 games in young Korean soccer players. Journal of Exercise Rehabilitation, 14 (2): 253-258.

Redkva, P.E., Paes. M.R., Fernandez, R., Da-Silva, S.G., (2018). Correlation between match performance and field tests in professional soccer players. Journal of Human Kinetics, 62 (1):213-219.

Reilly, T., Bangsbo, J., Franks, A., (2000). Anthropometric and physiological predispositions for elite soccer. J Sport Sci, 18 (9): 669-683.

Rodrigo, F.G., Teixeira, F.S., Guilherme, B., Lopez, D.G., Murua, J.A.H., Jimenez, R.J., Jose, A.P., (2010). Comparison of Technical and Physiological Characteristics of Prepubescent Soccer Players of Different Ages. Journal of Strength and Conditioning Research, 24 (7): 1790-1798.

Yanga, G., Leichtb, A.S., Lago, C., Gómez, M.A., (2018). Key team physical and technical performance indicators indicative of team quality in the soccer Chinese super league. Research in Sports Medicine 26 (2): 158-167.

Zagatto, A.M., Miyagi, W.E., Sakugawa, R.L., Papoti, M., (2013). Use of maximal running distance performed on Hoff test for anaerobic threshold prediction in soccer. Rev Bras Med Esporte, 19 (4): 267-270.

Zagatto, A.M., Papoti, M., Da Silva, A.S.R., Barbieri, R.A., Campos, E.Z., Ferreira, E.C., Loures, J.P., Chamari, K., (2016). The Hoff circuit test is more specific than an incremental treadmill test to assess endurance with the ball in youth soccer players. Biol. Sport, 33 (3): 263-268. 